\title{
What is Effective Feedback? A Comparison of Views of Students and Academics
}

\author{
Darren Coombes, MA \\ College of Human and Health Sciences, Swansea University, SA2 8PJ, Wales \\ Email of author d.p.coombes@swansea.ac.uk
}

\begin{abstract}
In recent years the literature regarding feedback has flourished with many researchers exploring the various factors related to student feedback. Researchers have focussed on individual aspects of feedback, such as timing or quality, and mainly explored the views of students to develop ways to increase the student satisfaction. However, with relatively low scores still being achieved through the National Student Survey (NSS), the question 'why are students unhappy with feedback?' still remains. The purpose of this research was to explore the perception of academic staff and students regarding what is effective feedback? A total of 9 students and 10 academics participated for this study. Participants were randomly allocated to either one-to-one interviews or focus groups. All collected data was analysed to highlight common themes between academics and students. The data revealed many inconsistencies in the provision of feedback and highlighted that there is no single factor resulting in student dissatisfaction. Three specific action plans were developed to help address the many contributing factors to students' dissatisfaction with feedback. These action plans will then aim to have a beneficial influence on the student experience and their learning process.
\end{abstract}

Keywords: Feedback; Higher Education; Grounded Theory.

DOI: $10.7176 / \mathrm{JEP} / 12-30-04$

Publication date:October $31^{\text {st }} 2021$

\section{Introduction}

Within higher education institutes the concept of feedback is considered an essential component for effective learning to take place and provides students with the opportunity for reflection and development (Weaver, 2006) and to enhance their learning strategies (Carless \& Boud, 2018). It is widely recognised as one of the most powerful influences on the student learning process and student achievement with some authors arguing that it ranks above students' personal attributes and the learning environments (Biggs, 2003; Hattie \& Timperley, 2007).

Despite the importance of feedback and its purpose for effective learning to take place, student satisfaction regarding feedback is significantly low compared to other aspects of higher education. This is evident from the UK National Student Survey (NSS) which in 2018 highlighted the students' relative dissatisfaction with the feedback they receive from higher education institutes (NSS, 2008). The calculated figures from this survey show that in 2018 only $73 \%$ of students in the UK scored positively regarding the feedback they received. Data from previous years are consistent with this figure (73\% in 2017, 74\% in 2016), indicating that this is an ongoing issue with student satisfaction and there is an essential requirement to improve these figures for future surveys to reflect the hard work performed by academics within higher education.

Previous research investigating the student feedback process have explored particular aspects relating to this process such as its value, quality and timing (O’Donovan, Price \& Rust, 2008; McCann \& Saunders, 2012; Hounsell, McCune, Hounsell \& Litjens, 2008; Marie, 2016). However, limited research has explored these aspects from both parties involved with this process (Mulliner \& Tucker, 2017; Bevan, Badge, Cann, Wilmott \& Scott, 2008). Regardless of all this research carried out to improve this process, the question 'why are the majority of students unhappy with feedback?' still remains. Therefore, the aim of this research was to explore the perceptions of academic staff and students regarding what is effective feedback.

\section{Method}

\subsection{Research design}

For the purpose of this study, a Grounded Theory (GT) approach to research was used. This form of qualitative research was performed to identify common themes that emerged from the rich data collected.

\subsection{Participants}

A total of 10 academic staff and 9 students from the College of Human and Health Sciences, Swansea University, volunteered to participate in this study. Academic staff were required to have a minimum of two years' experience in providing students with feedback from a varying range of assessments. Student volunteers were required to be within their second or third year of higher education. All participants for this study were recruited via email by an impartial third party and randomly assigned to one of the data collection categories. Participants were not required to participate in both areas of data collection. In order to eliminate potential bias, the author had no personal 
relationship with any participant.

\subsection{Data Collection}

In order to collect rich data, a triangulation approach for data collection was used to develop a comprehensive understanding of the research question. Two different formats of data collection were used; one-to-one interviews and focus groups (maximum of three participants) both consisting of open-ended questions and topics for discussion. Participants were informed to speak freely throughout each session to allow them to share any views regarding feedback, positive or negative, within a safe environment. All sessions were recorded using an audio device and a full transcript was documented.

\subsection{Data Analysis}

Analysis of the collected data was performed alongside the data collection phase, using a true grounded theory approach. The data was then analysed following a four step approach: Open coding, Focussed coding, Thematic coding, Selective coding. Once the raw data was fully analysed, the key findings were then discussed with the participants. This helped to ensure that the leading themes identified from the analysis process were valid.

\section{Results and Discussion}

Three leading themes were highlighted during the data analysis process (Figure 1). All leading themes are not considered to be independent factors as they are closely linked.

\subsection{Timing}

The leading theme of timing was the initial aspect that the majority of academics alluded to at the beginning of each session. The main rationale for academics wanting to express their opinions regarding this was due to the ever-increasing cohort sizes and short turnaround time to provide students with in-depth feedback (Yang \& Carless, 2013). Academic participants were under the impression that students require feedback quickly following an assessment and any rush in this process would significantly reduce its quality. A large proportion of academics further commented that even with limited turnaround times, the feedback provided is of a high quality and meets the university standards. However, further discussions revealed that if more time were to be dedicated to this process then this would positively reflect on the quality. The researcher also detected a sense of frustration from the academic participants when discussing this matter, suggesting that this has the potential to escalate into a major issue and without provisions in place could result in serious consequences (Hernández, 2012). A large number of student participants alluded to this aspect and fully appreciated the effort and time taken in producing feedback.

Dedicated time to provide feedback could improve its quality without causing a delay in the feedback process. If delays to students receiving feedback were to occur, the academics expressed that the students would then view such feedback negatively and decrease the student satisfaction, regardless of its quality. Student participants commented that there would be some slight annoyance if feedback were to be delayed as expectations to receive feedback on a certain date become diminished leading to a sense of frustration. However, all students commented that delayed feedback would not be viewed negatively and this should be reflected by an increase in its quality with clear applications to future assignments. This also highlights that academic staff want to provide feedback to a high standard in order to improve the students' learning process, fulfilling the main purpose of feedback within higher education but feel restricted. Allocated marking time is currently not scheduled in many higher education institutes and academic staff are required to develop feedback within the time they have available. This questions whether higher education institutes consider feedback equally important as activities already scheduled, such as lectures, within the student learning process.

\subsection{Value}

Academic participants continuously discussed their opinions that students only focus on the final mark achieved and do not pay attention to or even care about the feedback as they may view their grade as a reflection of their academic progress. The findings from this research found that the majority of students do value feedback as it aims to help them improve academically. A small minority of students did comment that the final mark was their ultimate goal and they would be more inclined to receive their grade rather than the feedback. The students who participated within this study were second and third year undergraduates, where their assessment grade will contribute to their final degree classification. Therefore, this may be viewed as 'understandable' but reduces the true value of feedback and the impact it can have.

All academic participants want the students to achieve their full academic potential and feel they do not provide feedback in a negative manner. However, further discussions found that the academics believed if the awarded mark does not meet the students' expectations then a negative perspective of the feedback is automatically created (Taras, 2006). Assuming that this perception is true by the academics then this could also suggest that students expected to achieve a good grade would receive better feedback. This aspect is ruled out within higher 
education institutes due to anonymous marking of assessments which also rules out potential bias, placing the entire expectation of the resulting mark on the student.

The aspect of viewing the feedback with a negative mind-set regarding the awarded mark was confirmed by a small portion of students. It was discussed that if a mark does not meet their expectations then they would view the feedback as negative, with one student using the word 'harsher'. The majority of students within higher education work extremely hard to produce an assignment that they feel is of high quality, which could result in a significant increase of their expectations to achieve a high mark. If the mark does not reflect this then it could prove to be detrimental on their perception of the feedback and result in such feedback becoming devalued, which may not be a true reflection concerning the quality of the feedback provided.

The majority of students still believed that the provision of feedback is a vital component in order to improve their work, regardless of their mark, and is a necessary tool to improve their learning process. This view may be due to the respect between both parties and viewing the academics as specialists within their field. From understanding these views it is apparent that students should be further educated with regards to the purpose of feedback in order for them to avoid a negative mind-set during interpretation and misinterpreting its content, ultimately having a beneficial influence of increasing its value.

\subsection{Quality}

The quality of feedback students received was a key discussion point during all sessions from both students and academics. The main concern from student participants was with regards to feedback being too vague and not providing specifics in order for them to act upon. When the aspect of providing more specifics within the feedback was raised with the academics the majority of participants were adamant they provide high quality feedback and aim to include specifics in order for students to improve. In contrast to this, a small number of academic participants expressed that large quantities of feedback they have observed through a moderation process does not provide the students with the key specifics that they require, suggesting a level of inconsistency between academics. Further comments from academics suggested that providing students with too many specifics would make their ability to act on the feedback too easy and potentially eliminate some of the necessary skills required when studying at a higher education institute (Gibbs \& Simpson, 2004).

Student participants further alluded to the quantity of feedback received and were confused how some academics could provide little feedback for their work and others deliver an abundance of feedback. Students further commented that vast amounts of feedback immediately indicates various areas for improvement and alters their approach in interpreting the feedback. Conversely, providing limited amounts of feedback could be viewed as highly specific but has the possibility to lack in sufficient detail regarding areas to improve. Academics discussing this aspect again alluded to the timing aspect and stated that there is no university policy stating how much feedback should be provided which further results in an inconsistent approach to student feedback.

Academic participants discussed their opinions that students do not fully understand the specific terminologies incorporated into the feedback and may view it as ambiguous. It was further discussed that if the students do not understand its content then they will devalue the feedback and perceive it as lacking in quality. This was confirmed by a large number of the students that expressed their frustration with some academics including terminologies unfamiliar to them with no further in-depth detail. Some academics shared this view with the students when discussing feedback provided by their peers through the moderation process. However, it may be argued that these complex terms within the feedback are commonly used within higher education institutes and students should be equipped to digest such terminologies in order to effectively act upon them (Blair \& McGinty, 2013).

In order for students to fully utilise the feedback they must firstly be able to understand it. There are many formats that could be explored in order to accomplish this; however, it is clear that some form of education into the various terminologies and phrases for students is required. This will then help to bridge the significant gap between receiving feedback and acting on it; improve the student learning process.

\subsection{Additional Findings}

Further analysis of the transcripts from academic sessions alone highlighted two additional themes (Figure 2).

Academic participants within this study suggested that in order for feedback to become effective there is a requirement for a strong academic-student relationship. Comments were made to suggest that the feedback process should be a joint effort and both parties should be working together, towards the same goal. The academic staff are to provide the feedback but the student must accept it in order to act on it, highlighting the importance of building a strong academic-student relationship based on trust and respect (Price, Handley, Millar \& O'Donovan, 2010). ${ }^{15}$ Building this two-way relationship can prove to be difficult due to potential barriers such as ever increasing cohort sizes, creating a direct influence on one-to-one interactions between academics and students. If these barriers are not tackled then there is a potential 'knock-on' effect for teacher evaluations, including the feedback provided. 
Academic participants often alluded to the various formats of feedback delivered throughout a module and were convinced students do not necessarily consider these as feedback. The majority of student interviews/focus groups focussed on feedback received from summative assignments that contribute to their overall module grade, with no consideration to other formats of feedback. Students may value the other formats of feedback at the time of delivery but do not consider them when completing final module evaluations. This highlights the importance of educating students the importance and various formats of feedback in order for them to fully appreciate its value.

\section{Conclusion}

Any contemplation in improving the effectiveness of feedback should consider the process as a whole rather than single factors. Future research should focus on the entire process to identify potential barriers which could reduce the effectiveness of feedback from the perspectives of both parties involved (academic and students). In addition to this, tackling small areas of dissatisfaction may highlight additional methods to help increase the satisfaction amongst academics and students. Three initial proposed methods include timetabling academic staff, educate new members of academic staff and the 3 A's of student feedback.

Timetabling academic staff - Assessment planners are developed at the beginning of each academic year, which would enable academic staff to block their calendar in advance and dedicate this time to developing and providing feedback.

Educate new members of academic staff - variation in feedback between academics can be reduced by esteemed academics, highly regarded for their feedback, providing assistance to new academic staff. This will also help to challenge the inconsistency of feedback received by students.

The 3 A's of Student Feedback - A greater emphasis should be placed on reducing the gap between the academic's feedback and the student appreciation of its importance. The '3A's of Student Feedback' is a proposed model aimed at bridging this gap to ensure students read (Acknowledge), fully understand (Accept) and are able to apply the necessary actions (Act) when receiving feedback.

\section{References}

Bevan, R., Badge, J., Cann, A., Willmott, C., \& Scott. J. (2008), "Seeing Eye-to-Eye? Staff and Student Views on Feedback", Bioscience Education 12(1), 1-15.

Biggs, J.B. (2003), “Teaching for Quality Learning at University: What the Student Does”. 2nd ed. Maidenhead: Open University Press; 2003

Blair, A. \& McGinty, S. (2013), "Feedback-Dialogues: Exploring the Student Perspective", Assessment and Evaluation in Higher Education 38(4), 466-476.

Carless, D. \& Boud, D. (2018), "The development of student feedback literacy: enabling uptake of feedback", Assessment \& Evaluation in Higher Education 43(8), 1315-1325.

Gibbs, G. \& Simpson, C. (2004), “Conditions under which assessment supports students' learning”, Learning and Teaching in Higher Education 1(1), 1-31.

Hattie, J. \& Timperley, H. (2007), "The Power of Feedback", Review of Educational Research 77(1), 81-112.

Hernández, R. (2012), "Does continuous assessment in higher education support student learning?", Higher Education 64(4), 489-502.

Higher Education Funding Council for England. 2018. Annual National Student Survey. Retrieved from http://www.hefce.ac.uk/lt/nss/results/2018/

Hounsell, D., McCune, V., Hounsell, J. \& Litjens, J. (2008), “The quality of guidance and feedback to students", Higher Education Research and Development 27(1), 55-67.

Marie, J.A. (2016), "Student Views on the Value of Feedback", Journal of Education and Training Studies 4(6), 207-213

McCann, L. \& Saunders, G. (2012), "Exploring student perceptions of assessment feedback", The Higher Education Academy. SWAP; 2012

http://www.swap.ac.uk/docs/projects/rpt_mccann_online.pdf

Mulliner, E. \& Tucker, M. (2017). "Feedback on feedback practice: perceptions of students and academics", Assessment and Evaluation in Higher Education 42(2), 266-288.

O’Donovan, B., Price, M. \& Rust, C. (2008), "Developing student understanding of assessment standards: A nested hierarchy of approaches", Teaching in Higher Education 13(2), 205-216.

Price, M., Handley, K., Millar, J. \& O’Donovan, B. (2010), "Feedback: All That Effort, but what is the Effect?", Assessment and Evaluation in Higher Education 35(3), 277-289.

Taras, M. (2006), "Do unto others or not: equity in feedback for undergraduates", Assessment and Evaluation in Higher Education 31(5), 365-377.

Weaver, M.R. (2006). "Do students value feedback? Student perceptions of tutors' written responses", Assessment and Evaluation in Higher Education 31(3), 379-394.

Yang, M. \& Carless, D. (2013), "The Feedback Triangle and the Enhancement of Dialogic Feedback Processes", 
Teaching in Higher Education 18(3), 285-297.

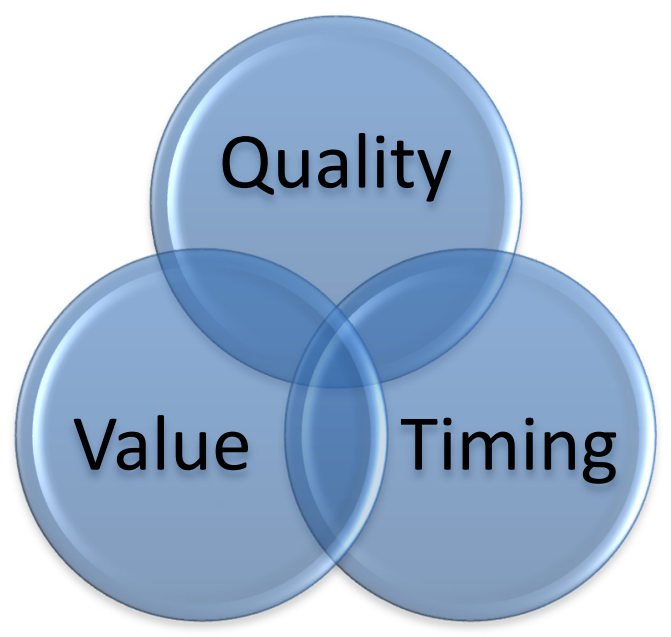

Figure 1: Leading themes that emerged between the two groups of participants.

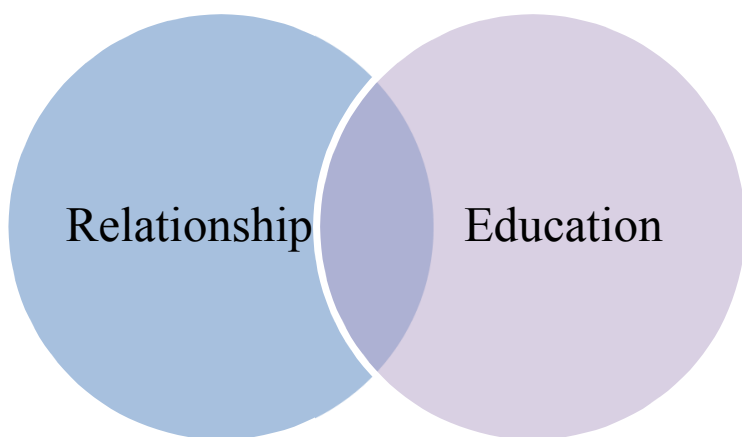

Figure 2: Additional themes that emerged from academic participants alone.

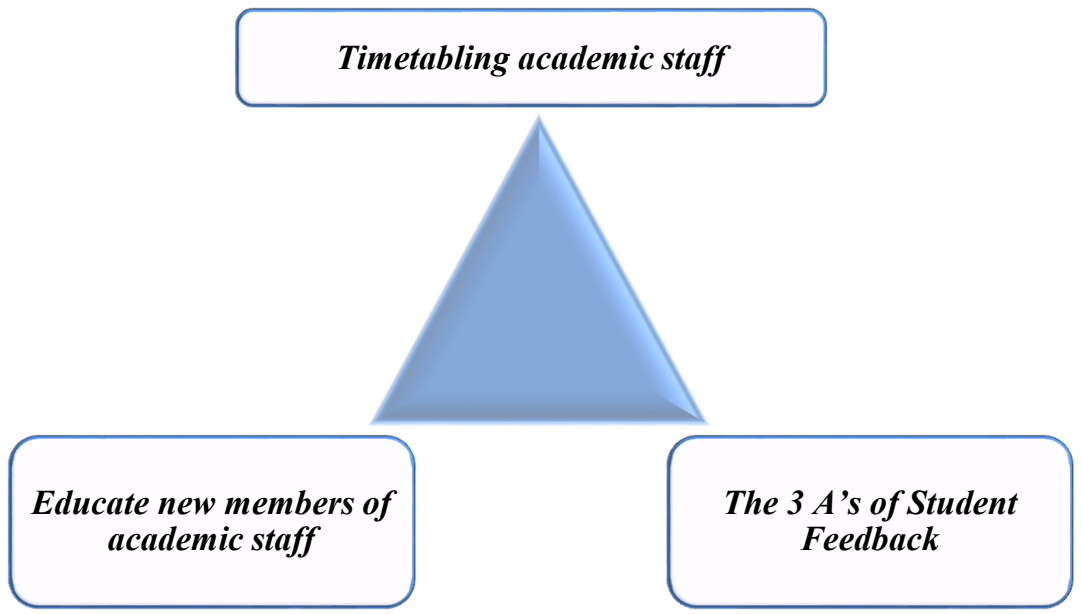

Figure 3: Proposed methods to tackle dissatisfaction with the feedback process.
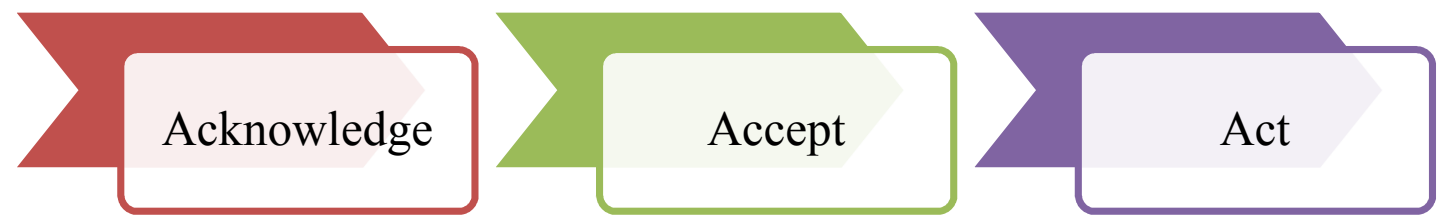

Figure 4: The 3A's of Student Feedback. 